\title{
Learning Disabilities and Low Social Status: The Role of Peer Academic Reputation and Peer Reputation of Teacher Liking
}

\author{
Lisa van der Sande, MSc', Marloes M. H. G. Hendrickx, PhD', \\ Henrike J. Boor-Klip, MSc ${ }^{2}$, and Tim Mainhard, PhD'
}

\begin{abstract}
Although many studies have found that children with learning disabilities (LD) are less liked by peers than children without LD, the results are not unequivocal. In the present study, we investigated the social status (in terms of likeability and popularity) of children with LD by considering peer academic reputation and peer reputation of teacher liking. These variables are potentially important alternative factors for differences in social status between children with and without LD. Fifth-grade students $\left(n=1,453 ; M_{\text {age }}=10.60\right)$ in 58 classes in the Netherlands completed peer nominations for academic reputation, teacher liking, and social status. The data were analyzed with Bayesian structural equation modeling. The associations between LD and social status were completely mediated by the lower peer academic reputation of children with LD. As expected, peer reputation of teacher liking served as a protective factor against low social status for children with low peer academic reputation in general but not specifically for children with LD. Implications for research and practice are discussed.
\end{abstract}

\section{Keywords}

academic reputation, Bayesian statistics, learning disability, likeability, popularity, teacher-student relationships

Many children with learning disabilities (LD) have, in addition to problems with academic skills, problems with peer relations (e.g., Bursuck, 1989; Estell et al., 2008; Greenham, 1999; Kavale \& Forness, 1996; Terras, Thompson, \& Minnis, 2009), which places them at a double risk for future maladjustment. Although many studies have shown that children with LD have a lower social status than children without LD (for a meta-analysis, see Nowicki, 2003), the results are not unequivocal. Some studies showed no differences in social status between children with and without LD (e.g., Bakker, Denessen, Bosman, Krijger, \& Bouts, 2007). As more and more children with LD are included in regular education (Bakker et al., 2007; Waitoller \& Artiles, 2013), insight into the social status of children with LD in mainstream classrooms is important.

Different explanations are possible regarding the mixed findings of previous studies on the social status of children with LD. First, the operationalization of LD differs across studies, varying from an intelligence-achievement discrepancy to definitions with strict exclusionary criteria or placement in special education classes (Bakker et al., 2007; Greenham, 1999; Nowicki, 2003). In the present study, a diagnosis of dyslexia or dyscalculia was used as the criterion (American Psychiatric Association, 2013; Bakker et al., 2007). A second explanation for the mixed results may be that the roles of peer academic reputation (PAR; Bakker et al., 2007; Haager \& Vaughn, 1995; Nowicki, 2003; Valås, 1999) and peer reputation of teacher liking (PRTL; Chang et al., 2007; Farmer, McAuliffe Lines, \& Hamm, 2011; Hughes, Cavell, \& Willson, 2001; Hughes \& Kwok, 2006) were often ignored in studies investigating the social status of children with LD. Not only have these factors been connected to social status, but it is also assumed that achievement (or peer perceptions thereof) and teacher liking differ between children with and without LD (Nowicki, Brown, \& Stepien, 2014; Terras et al., 2009; Valås, 1999; Vaughn, Hogan, Kouzekanani, \& Shapiro, 1990). In the current study, we therefore included both PAR and PRTL to gain a better understanding of the connection between having LD and children's social status in upper classes in Dutch primary schools.

\footnotetext{
'Utrecht University, The Netherlands

${ }^{2}$ Radboud University Nijmegen, The Netherlands

Corresponding Author:

Tim Mainhard, Utrecht University, Heidelberglaan I, PO Box 80I40, Utrecht, 3508 TC, The Netherlands.

Email:m.t.mainhard@uu.nl
} 


\section{Social Status of Children With LD}

According to Cillessen and Marks (2011), social status comprises the following two constructs: likeability and popularity. Likeability refers to personal preference and peer affiliation, while popularity is based on group consensus about someone's position and is associated with power and visibility in a group (Cillessen \& Marks, 2011; Lease, Musgrove, \& Axelrod, 2002). An important distinction is that likeability is based on peers' individual feelings about a student, whereas popularity is based on peers' assessment of group feelings (Cillessen \& Marks, 2011).

Children's social status is important for their socialemotional and academic development, both short- and long-term (Greenham, 1999; Nelson \& Dishion, 2004). In particular, likeability is associated with emotional adjustment (Cillessen \& Rose, 2005). Low likeability can lead to loneliness and depression (Valås, 1999) and lower school and work engagement (Nelson \& Dishion, 2004). The effects of popularity on school adjustment are more divergent. Although the short-term effects are mainly positive, popularity may lead to maladjustment in the long term (Cillessen \& Rose, 2005), especially if popularity is associated with high levels of aggression (Troop-Gordon, Visconti, \& Kuntz, 2010). In the present study, the associations of LD with both social status constructs are investigated.

Although LDs are mainly characterized as problems with academic achievement, research has increasingly focused on the social skills and social status of children with LD as side effects of the disabilities (Kavale \& Mostert, 2004). Indeed, a meta-analysis showed that approximately $75 \%$ of children with LD also have deficits in social skills (Kavale \& Forness, 1996), which places them at risk for a low social status (Estell et al., 2008; Vaughn, Elbaum, \& Boardman, 2001). Furthermore, being labeled with LD may lead to a lower social status because of stigmatization (Valås, 1999). A diagnosis of LD may influence children's self-worth (Bakker et al., 2007; La Greca \& Stone, 1990; Valås, 1999) and peers' perceptions of children with LD (Estell et al., 2008; Nowicki, 2012; Valås, 1999); being perceived as "different" may also affect the social status (Nowicki et al., 2014).

In most research focusing on the social status of children with LD, likeability was used as the sole outcome measure. One study that focused on likeability and popularity did not find a significant difference regarding the popularity of children with LD, whereas a difference in likeability was found (Estell et al., 2008). Despite evidence that children with LD are relatively less liked, it is important to keep in mind that not all children with LD have problems with social functioning and social status (Greenham, 1999;
Vaughn et al., 2001). In fact, it has been shown that children with LD belong to a group of friends as often as children without LD (Estell et al., 2008) and that their social status is comparable to that of average-achieving children (Bakker et al., 2007). Given these inconclusive results, the aim of the present study is to obtain more insight into the social status of children with LD while considering other factors that may explain a child's social status, such as PAR and PRTL.

\section{Peer Academic Reputation}

Low PAR might be the most important factor underlying the lower social status of children with LD (e.g., Haager \& Vaughn, 1995; Valås, 1999). Children with LD have low academic achievement, particularly in a specific domain (Fletcher, Stuebing, Morris, \& Lyon, 2013). Low achievement is also linked to social status (Bakker et al., 2007; Haager \& Vaughn, 1995; Nowicki, 2003; Valås, 1999) because it can influence children's PAR-for example, when they receive negative comments on their schoolwork (Haager \& Vaughn, 1995; Vaughn et al., 1990). Since negative peer perceptions seem the most important reason why low achievement is linked to a low social status, PAR is used in the present study. Indeed, PAR is positively related to likeability (Vannatta, Gartstein, Zeller, \& Noll, 2009). Given the close connection between LD and PAR, it is surprising that no studies were found in which their combined effects on the social status of children with LD were investigated.

LDs may still have an effect over and above PAR. Some studies compared children with LD with low-achieving students (e.g., Bakker et al., 2007; Haager \& Vaughn, 1995; Valås, 1999), which again led to inconclusive results. Some studies found that children with LD have a lower social status than do low-achieving children, which seems to support the view that low achievement alone cannot account for their lower social status (Bursuck, 1989; La Greca \& Stone, 1990; Valås, 1999). In contrast, other studies found that the social status of children with LD was comparable to or even higher than the social status of low-achieving children (Bakker et al., 2007; Haager \& Vaughn, 1995; Vaughn, Elbaum, \& Schumm, 1996; Vaughn, Haager, Hogen, \& Kouzekanani, 1992). A diagnosis of LD may even have positive effects because it can serve as an external factor explaining the low achievement, thereby leading to a better appreciation of a child's strengths and weaknesses (Terras et al., 2009; Valås, 1999). In addition, peers might notice that the low achievement of children with LD is mostly restricted to one academic domain (Bakker et al., 2007; Terras et al., 2009). Therefore, a diagnosis of LD might also buffer the negative effects of PAR on social status. 


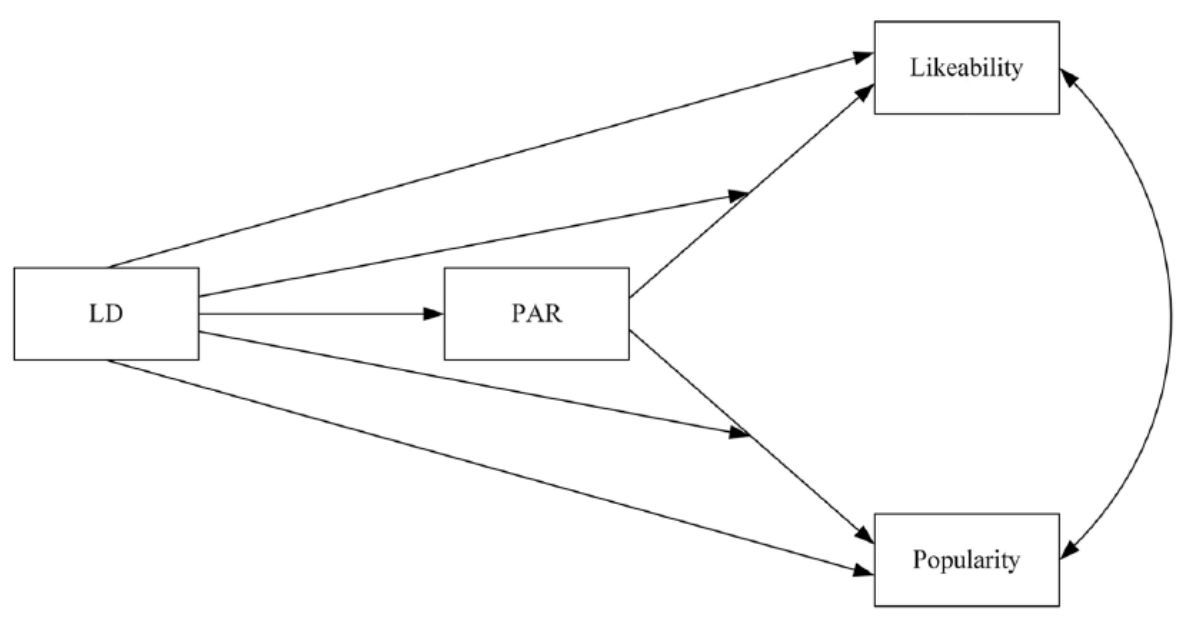

Figure I. Hypothesized moderated mediation model. LD = learning disabilities; PAR = peer academic reputation.

\section{Peer Reputation of Teacher Liking}

Another explanation for the mixed findings regarding the connection between LD and social status may be that the role of the teacher has largely been disregarded (cf. Farmer et al., 2011). Indeed, children with LD seem to receive more negative attention from their teachers than other children (Haager \& Vaughn, 1995; Terras et al., 2009), which may also explain a lower social status. Teachers can influence the perceptions that children have about their classmates by serving as a social referent (Hughes et al., 2001). Social referencing assumes that children's likeability is partly based on information that peers derive from the interactions between the teacher and that child (Chang et al., 2007; Farmer et al., 2011; Hughes et al., 2001; Vaughn et al., 2001). These interactions inform peers about a child's competencies and the teacher's liking of a child, which peers are inclined to adopt as their own (Chang et al., 2007; Hughes et al., 2001). Therefore, PRTL could contribute to likeability (Chang et al., 2007; Hughes et al., 2001; Hughes \& Kwok, 2006).

Importantly for the context of the current study, in addition to a positive effect of supportive teacher-student interaction on likeability in general, there is some evidence that a supportive relationship with the teacher is particularly predictive of the likeability of children with a low PAR (Hughes, Im, \& Wehrly, 2014). PRTL might thus serve as a protective factor against low likeability by peers, specifically for children with LD and a low PAR. In addition to positive teacher-student interactions, popularity is, paradoxically, related to negative interactions-possibly because children's central position in the peer group is emphasized if they are having a conflicted relationship with the teacher and because adult-defying behavior is considered "cool" (De Laet et al., 2014). Therefore, PRTL is expected to be more predictive of likeability than of popularity.

\section{Present Study}

What we have discussed so far stresses the importance of considering PAR and PRTL to obtain a better understanding of the social status of children with LD. This results in the following research questions:

Research Question 1: How are LD and PAR associated with social status?

Research Question 2: Does PRTL moderate the effects of LD and PAR on social status?

We tested a moderated mediation model to disentangle the associations among LD, PAR, and social status (see Figure 1). It was hypothesized that children with $L D$ have a lower social status than children without LD, which is (partly) mediated by a low PAR. The moderating effect of LD on the associations between PAR and social status was examined to determine if this association differed between children with and without LD.

As shown in Figure 2, PRTL is added to the hypothesized model. PRTL was expected to be particularly predictive of likeability and, to a lesser extent, popularity. It was hypothesized that PRTL would be more predictive of social status for children with a low PAR than for children with an average or high PAR (i.e., a protective factor against low social status, modeled as a moderator) and possibly also for children with LD.

\section{Method}

\section{Participants}

The present study was part of a larger research project focusing on the social classroom climate in an upper primary schools. Data were collected in the fall of 2012, at 


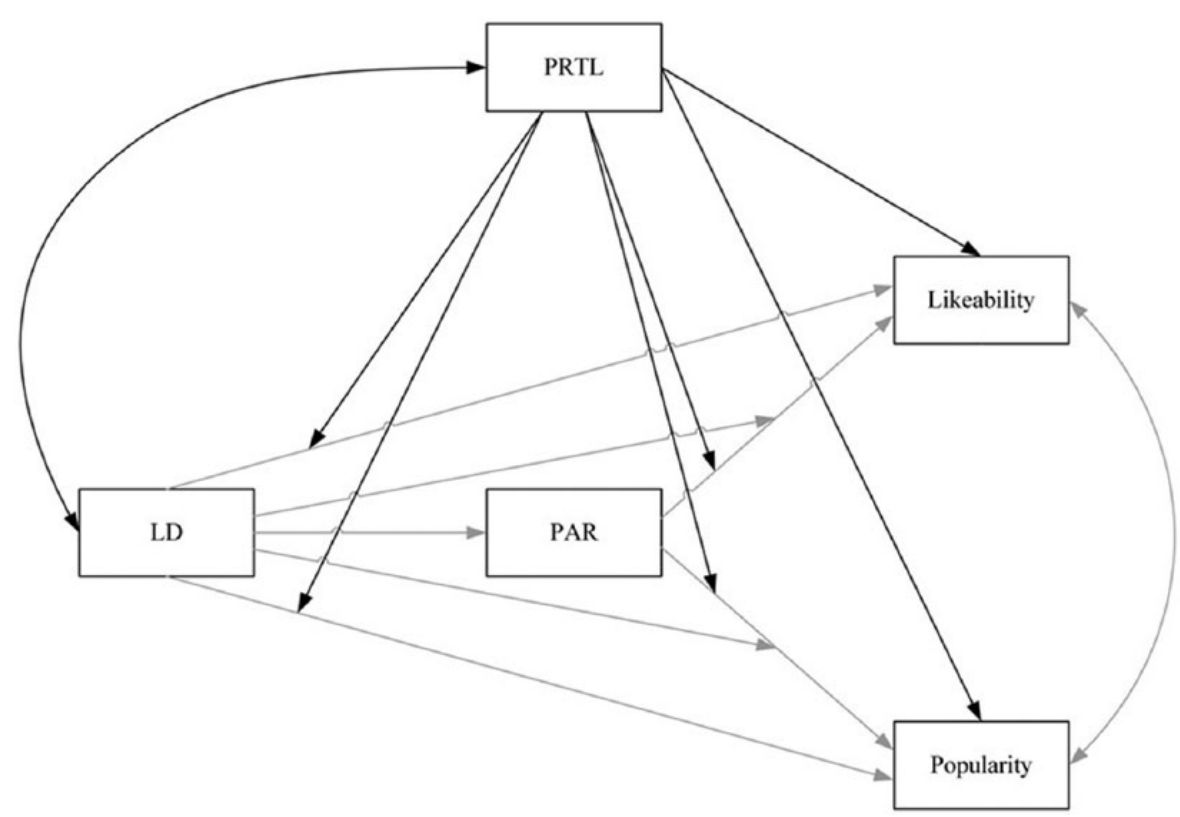

Figure 2. Hypothesized model including PRTL. LD = learning disabilities; $P A R=$ peer academic reputation; $P R T L=$ peer reputation of teacher liking.

least 1 month after the start of the school year, to ensure that all teachers and children knew one another reasonably well. This is considered a sufficient period, as most children had already known one another from previous years. Schools located in the middle, south, and east of the Netherlands were contacted and informed about the goals of the study. Fifty-nine teachers working at 41 schools participated. One class was excluded from the present study because a second teacher was present in the class at all times. Only gradehomogenous classes were included in the study (i.e., classes contained only fifth-grade students), with class size ranging from 18 to $34(M=26.17, S D=3.72)$.

For 1,496 of 1,518 children (98.6\%), parental consent was given (706 girls, 789 boys). Forty-three children were absent on the day of data collection; thus, peer nominations were completed by 1,453 children. As absent children could also be nominated, data are available for all 1,496 children with parental consent. Their ages ranged from 8 to 12 years $(M=10.60, S D=0.50)$. With parental consent, a diagnosis of dyslexia or dyscalculia, as present in the schools' records, was used as an index for having LD. In the Netherlands, a diagnosis of dyslexia is set if the criteria of a reading lag and didactic resistance are met: The proficiency level of reading at the word level and/or spelling is significantly lower than the level requested of an individual, given his or her age and circumstances, and the problem in learning and applying reading and/or spelling on word level persists, even when adequate remedial instruction and exercise are provided (Kleijnen et al., 2008). For dyscalculia, the three criteria of severity, a lag, and didactic resistance are set: There is a significant lag in arithmetic as compared with peers with equal age and/or educational level, which hinders the person in daily life; there is a significant lag in arithmetic as compared with what can be expected per the individual development of a person; and there is a persistent problem resistant to specialized help (Van Luit, Bloemert, Ganzinga, \& Mönch, 2012). In the current sample, 127 children $(8.5 \%$; 52 girls, 75 boys) were diagnosed with LD (122 dyslexia, 4 dyscalculia, and 1 both). This percentage closely resembles the prevalence of the 10-year-old children diagnosed with dyslexia in the Netherlands in 2011 to 2013 (8.6\%; Statistics Netherlands, 2015). For dyscalculia, this information was not available (Statistics Netherlands, 2015).

For every classroom, one teacher participated. If two or more teachers were working part-time, the teacher who spent the most hours in the classroom was selected (37 women, $21 \mathrm{men})$. Teachers' ages ranged from 24 to $62(M=$ $41.25, S D=11.91)$, and their teaching experience ranged from 1 to 39 years $(M=15.17, S D=10.99)$.

\section{Measures}

PAR, PRTL, and social status were measured through peer nominations. For all peer nominations, children were asked to nominate an unlimited number of their classmates who best fitted a certain description. Children completed the questionnaires individually on netbook computers in their classroom, with privacy and confidential data handling 
guaranteed. Cross-sex nominations were allowed, and children who were absent or not consented to participate could also be nominated. Nominations of children without parental consent were subsequently excluded from the data set.

Peer academic reputation. PAR was tapped with the item "Which classmates get good grades?" PAR was correlated with both a grade provided by the teacher to assess children's achievement $(r=.67)$ and their standardized test results $(r=.66)$, which indicates a substantial but not complete overlap with actual performance. The number of received nominations was divided by the maximum number of nominations (i.e., the number of children in a class) to obtain a proportion score and enable fair comparisons across classes with differing sizes.

Peer reputation of teacher liking. PRTL was measured with the item "Which classmates are liked most by the teacher?" In this item, "the teacher" was replaced by the name of the involved teacher. Similar to PAR, a proportion score was calculated by dividing the number of received nominations by the maximum number of nominations.

Social status. Likeability and popularity were used as indicators of social status. Likeability was measured with the items "Which classmates do you like most?" and "Which classmates do you like least?" ( $r=-.36)$. For popularity, the following items were used: "Which classmates are most popular?" and "Which classmates are least popular?" $(r=$ $-.41)$. Scores for likeability and popularity were computed as the difference between the proportion scores on these items.

\section{Data Analysis}

To analyze our models (see Figure 1 and 2), structural equation modeling based on Bayesian estimators was run in Mplus 7.3 (L. K. Muthén \& Muthén, 1998-2012). Objective Bayesian estimation (i.e., with uninformative priors) was used since no research was found that included PAR while investigating the social status of children with LD. Bayesian estimation was selected because of its possibility to address nonnormality and small sample sizes (Hox, Moerbeek, Kluytmans, \& Van de Schoot, 2014; B. Muthén, 2010; B. Muthén \& Asparouhov, 2012; Van de Schoot et al., 2013). Although the total sample size was quite large, the number of children diagnosed with LD was much smaller (127 of $1,496)$. Another advantage of Bayesian statistics is the more straightforward interpretation of the $p$ value (Klugkist, van Wesel, \& Bullens, 2011). In contrast to the $p$ value in frequentist statistics, which represents the probability of obtaining the observed or more extreme data if the null hypothesis is true, probability in Bayesian statistics is defined as the degree of belief that a hypothesis is true
(Kaplan \& Depaoli, 2012; Klugkist et al., 2011). All unknown parameters are described by a probability distribution in Bayesian estimation because they are assumed to be uncertain (Van de Schoot et al., 2013). The $p$ value of a parameter estimate represents the proportion of this distribution that is in the direction other than the estimated parameter (B. Muthén, 2010).

The default settings of Bayesian estimation in Mplus were used (B. Muthén, 2010). For both models, the number of iterations was increased several times, until the parameter estimates did not change anymore $(150,000$ for both models; B. Muthén, 2010). Visual inspection of the plots (trace plots and autocorrelation plots) and proportional scale reduction factors close to 1 led to additional support of the adequate convergence for the models (B. Muthén, 2010; Van de Schoot et al., 2013). The model fit was analyzed with the posterior predictive $p$ value and the $95 \%$ confidence interval for the difference between the observed and the replicated chi-square values. Posterior predictive $p$ values close to .50 are indicators of a good model fit, while values close to 0 or 1 indicate a bad model fit (Gelman, 2013; Van de Schoot et al., 2013). If the posterior predictive $p$ value is .50, half of the chi-square values obtained in the data generated by the model exceed the chi-square value of the observed data. In well-fitting models, there is little discrepancy between the actual data and the data generated by the model (Van de Schoot et al., 2013). Therefore, if the 95\% confidence interval for the difference between the observed and replicated chi-square values includes zero, a model can be deemed plausible (B. Muthén, 2010). Furthermore, information is provided about all distinctive paths in the model. If the $95 \%$ Bayesian credible interval of a parameter estimate ranges from negative to positive, it is not possible to state the direction of that effect with $95 \%$ certainty (Van de Schoot \& Depaoli, 2014; Van de Schoot et al., 2013). These paths were not maintained in the model to obtain a clearer overview of the variables associated with the social status of children with LD. For a comprehensive overview of Bayesian statistics, see Van de Schoot et al. (2013), and for an overview of Bayesian analysis in Mplus, see Kaplan and Depaoli (2012) and B. Muthén (2010).

The analyses accounted for the nesting of the data by selecting the multilevel option in Mplus and specifying that all children were nested in classes. First, an intercept-only model was tested to analyze the amount of variance in likeability and popularity at the individual and classroom levels. Next, a moderated mediation model was tested, including LD $(0=$ no LD, $1=\mathrm{LD})$, PAR, likeability, and popularity. Finally, PRTL was added as a predictor to the model, including its interactions with LD and PAR. In both models, gender was included as a covariate $(0=$ boys, $1=$ girls) because of possible associations between gender, on one hand, and LD, PAR, PRTL, and social status, on the other (e.g., Bakker et al., 2007; Walker \& Nabuzoka, 2007). 
Table I. Spearman's Correlations and Descriptive Statistics $(n=1,496)$.

\begin{tabular}{|c|c|c|c|c|c|c|c|}
\hline & 1 & 2 & 3 & 4 & 5 & $M(S D)$ & Range \\
\hline I. Gender & - & & & & & & \\
\hline 2. LD & -.04 & - & & & & & \\
\hline 3. PAR & -.04 & $-.21^{* * * *}$ & - & & & $.25(.24)$ & $.00,1.00$ \\
\hline 4. Likeability & $.18 * * *$ & -.05 & $.39 * * *$ & - & & $.04(.18)$ & $-.72, .54$ \\
\hline 5. Popularity & $-.08 * *$ & .00 & $.22 * * *$ & $.36 * * *$ & - & $-.02(.30)$ & $-.94, .95$ \\
\hline 6. PRTL & $.38 * * * *$ & -.04 & $.27 * * *$ & $.37 * * *$ & $-.05 *$ & $.29(.16)$ & $.00, .89$ \\
\hline
\end{tabular}

Note. Gender $(0=$ boys, I = girls $)$. LD = learning disability $(0=$ no LD, I = LD); PAR = peer academic reputation; PRTL = peer reputation of teacher liking.

$* p<.05 . * * p<.01 . * * * p<.001$

\section{Results}

\section{Preliminary Analyses}

Data were assessed for (multivariate) outliers, normality, and linearity. All values were within the possible range. One multivariate outlier was detected by a Mahalanobis distance calculation procedure. Because the values of this participant were deemed plausible, this case was kept in the data. All data were normally distributed, except for PAR, which had a positively skewed distribution. However, this is not assumed to be problematic with Bayesian estimation (Muthén \& Asparouhov, 2012). No other violations of assumptions were detected.

Table 1 presents the descriptive statistics for all variables and correlations. Spearman's correlations were used, given the nonnormality of some of the variables. LD was negatively related to PAR, indicating that children with LD are perceived by peers as having lower achievement than children without LD. No significant correlations were found between LD and likeability, popularity, or PRTL.

For both likeability and popularity, the nesting effect was low (intraclass correlations $=.03$ and .01 , respectively). Although $<3 \%$ of the variance was located at the classroom level, the multilevel option was used to correctly adjust the standard errors of the estimated coefficients (Hox, 2010).

\section{Associations Among LD, PAR, and Social Status}

The hypothesized moderated mediation model had a poor model fit (posterior predictive $p$ value $=.00$ ). Therefore, some modifications were necessary. The paths with a $95 \%$ credible interval including zero were removed from the model, which resulted in a considerable improvement in the model fit (posterior predictive $p$ value $=.42$ ). The model was deemed acceptable, as the $95 \%$ confidence interval $[-15.82,18.85]$ for the difference between the observed and replicated chi-square values included zero (B. Muthén, 2010). In the final model, the variables explained $14.9 \%$ of the variance for likeability and $4.4 \%$ for popularity.

The results of this model are displayed in Figure 3. As shown in the figure, likeability and popularity were correlated $(r=.35)$. The associations between LD and likeability and popularity were fully mediated by PAR. LD was negatively related to PAR $(\beta=-.19)$, which in turn led to a lower social status because of the positive associations between PAR and likeability $(\beta=.34)$ and popularity $(\beta=.19)$. LD had a small indirect effect via PAR on likability $(\beta=-.06)$ and popularity $(\beta=-.04)$. No direct effects of LD on social status were found, and neither were interaction effects of LD and PAR on social status. The covariate gender was related to PAR, likeability, and popularity. On average, girls had a somewhat lower PAR than boys $(\beta=-.07)$ and a higher likeability $(\beta=.21)$ but were observed as less popular $(\beta=-.07)$.

\section{Perceived Teacher Liking}

PRTL was added to the model, including its interaction with $\mathrm{LD}$ and PAR, to investigate the direct and moderating effects of PRTL. Again, we adjusted the hypothesized model by deleting paths for which little support was found. Furthermore, the correlation between PRTL and PAR was added to obtain a better model fit. The model including PRTL fitted the data slightly better than the model without PRTL (posterior predictive $p$ value $=.46$ ). As in the first model, the $95 \%$ confidence interval for differences between the observed and replicated values included zero [ -21.31 , 23.14], indicating an acceptable model (B. Muthén, 2010). The explained variance increased $\left(R^{2}=21.2 \%\right.$ for likeability and $5.2 \%$ for popularity); thus, the inclusion of PRTL led to an additional $6.3 \%$ in explained variance for likeability and $0.8 \%$ for popularity. This implies that considering PRTL helps to understand social status (particularly likeability). Figure 4 displays the final model including PRTL.

A direct effect of PRTL on likeability was found $(\beta=$ .36) but not on popularity. PRTL moderated the effect of PAR on likeability $(\beta=-.23)$ and popularity $(\beta=-.20)$. For both likeability and popularity, the slope for children with a low PRTL was steeper than for children with high levels of PRTL (see Figure 5). With lower levels of PRTL, differences in social status between children with high and low PAR were more pronounced, indicating that PRTL can 


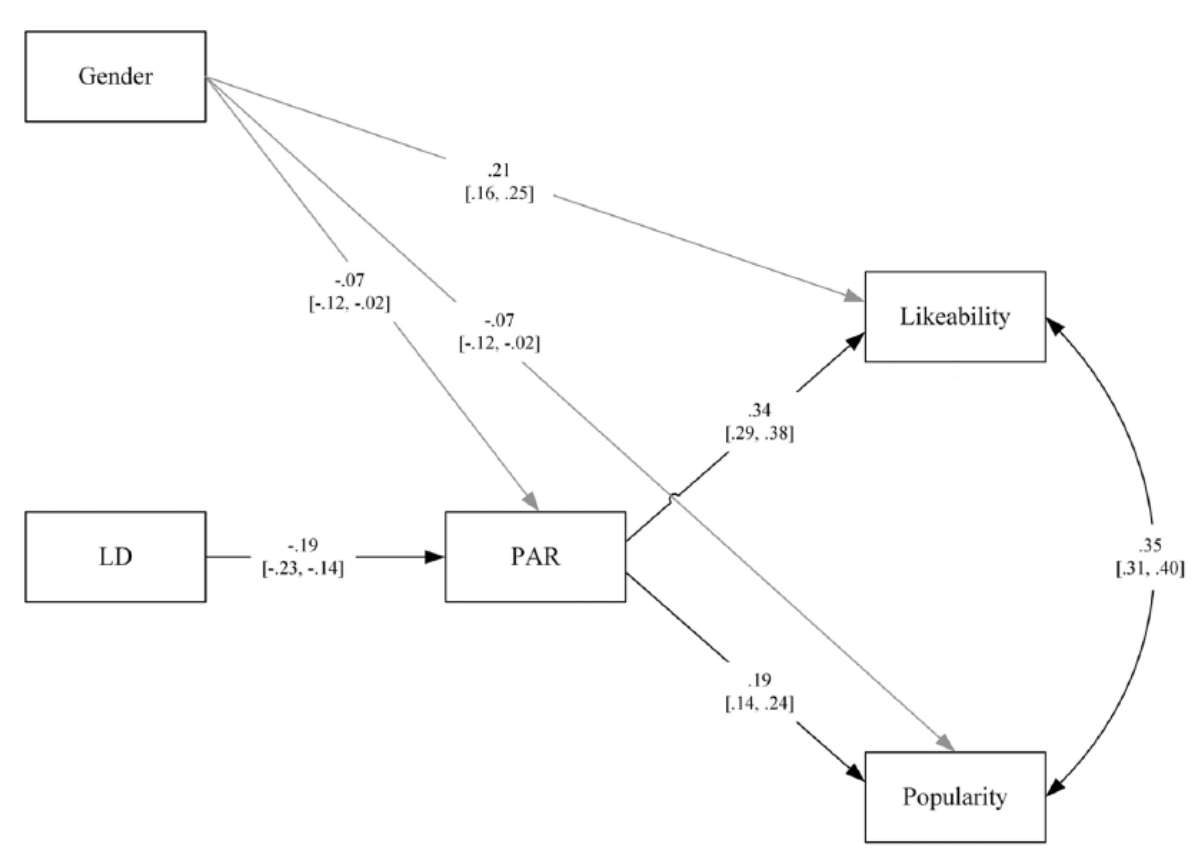

Figure 3. Standardized estimates for associations among LD, PAR, and social status $(n=1,496) ; 95 \%$ credible intervals are presented within square brackets. Paths with a credible interval including zero were removed from the model. $L D=$ learning disabilities $(0=$ no LD, I = LD); PAR = peer academic reputation; gender ( 0 = boys, I = girls $)$.

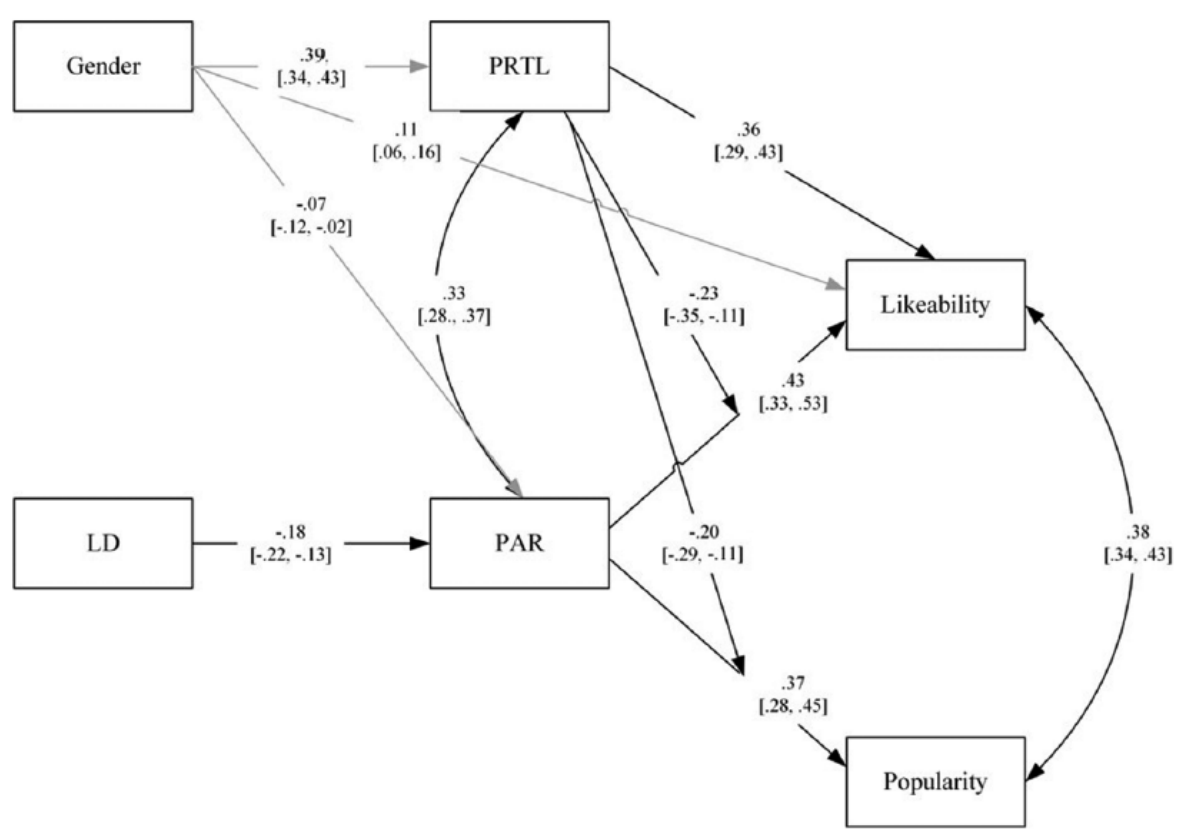

Figure 4. Standardized estimates for the model with PRTL included $(n=1,496)$; $95 \%$ credible intervals are presented within square brackets. Paths with a credible interval including zero were removed from the model. $L D=$ learning disabilities $(0=$ no $L D, I=L D)$; $\mathrm{PAR}=$ peer academic reputation; $\mathrm{PRTL}=$ peer reputation of teacher liking. Gender $(0=$ boys, $\mathrm{I}=$ girls $)$. 

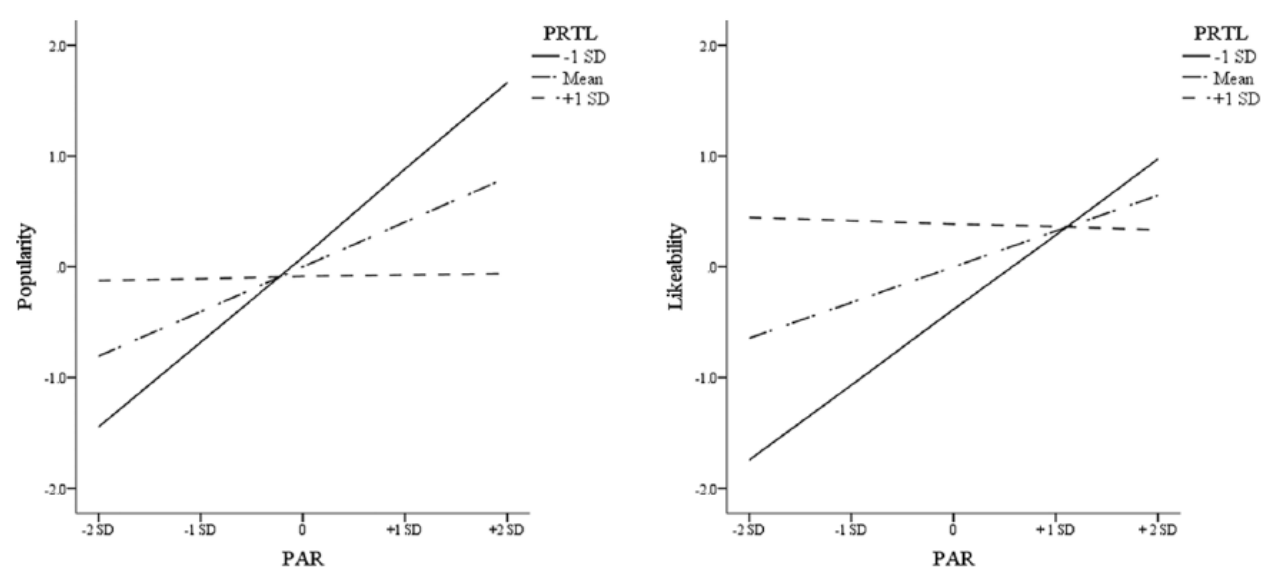

Figure 5. Interaction effects of PAR $\times$ PRTL on likeability and popularity. PAR = peer academic reputation; $P R T L=$ peer reputation of teacher liking.

serve as a protective factor against a low social status for children with low PAR.

No relationship was found between LD and PRTL. However, PRTL moderated the effect of LD on social status indirectly via PAR. The indirect effect of LD on social status via PAR became somewhat larger by the inclusion of $\operatorname{PRTL}(\beta=-.08$ for likeability and $\beta=-.06$ for popularity).

By including PRTL and its moderating effects, some other estimates changed slightly (compare Figures 3 and 4). The associations between gender and popularity faded, which suggests that PRTL can explain the differences in popularity between boys and girls. Girls were, on average, perceived as being more liked by the teacher than boys $(\beta=$ .39). Furthermore, PRTL was related to PAR $(r=.33)$, indicating that children who are perceived by peers as having high achievement are also perceived as being liked more by the teacher.

\section{Discussion}

The aim of the present study was to obtain more insight into the social status of children with LD by considering peer perceptions of achievement and teacher liking. PAR appeared to be the most important factor explaining the associations between LD and social status. Having LD was associated with a lower PAR, which was in turn related to a lower social status. Children might be aware of the achievement levels of their classmates - for example, when they have to read aloud during class or when they frequently do not know the answers to questions asked by the teacher. This might influence peer perceptions and, in turn, the social status of children with low achievement. LD was not directly related to a lower social status. Thus, no support was found for the hypothesized stigmatizing effect of a diagnosis of LD. Children with and without LD also did not differ on PRTL, suggesting that children with LD are not perceived by peers as being more or less liked by the teacher than children without LD. PRTL moderated the associations between PAR and social status: PRTL compensated to a certain degree for the negative perceptions that peers had of children with a low PAR, thus serving as a protective factor against low social status.

The results are in line with studies showing that children with LD and, therefore, lower achievement (as perceived by peers) are at a greater risk of rejection by peers (Haager \& Vaughn, 1995; Vaughn et al., 1996). However, the indirect effect of LD via PAR on social status was quite small. On a more positive note, the results obtained by Bakker et al. (2007) showing that LD does not lead to a lower social status per se were confirmed in the present study. This seems to support that most children with LD have an average social status.

In research on the social status of children with LD, an agreement regarding the direct effect of LD on social status, in addition to low achievement (or peer perceptions thereof), is lacking. The present study supports the view that a diagnosis as such is not negatively associated with social status (e.g., Haager \& Vaughn, 1995) but that the effect is completely mediated by a lower PAR. A possible explanation for the absence of an added direct effect of LD on social status in the present study, which was demonstrated by other studies (Bursuck, 1989; La Greca \& Stone, 1990; Valås, 1999), may be the difference in the definitions of LD that were used (Fletcher et al., 2013; Greenham, 1999). The definition in the present study was probably more restricted than those used in some other studies. Some studies used only a discrepancy between intelligence and achievement as an indicator of $\mathrm{LD}$, without any other exclusionary criteria (e.g., Bursuck, 1989). However, this is assumed to be problematic (Fletcher et al., 2013; Scruggs \& Mastropieri, 2002) since there can be various other causes of an intelligence-achievement discrepancy other than LD, such as 
attention deficit (Hinshaw, 1992). Attention deficits may be more visible for classmates than deficits in reading, written expression, or mathematics because they often include more socially aversive behavior and consequently affect social status more directly (Willcutt et al., 2007). This would explain why some studies found, in contrast to the present study, a direct effect of LD on social status.

Another possible explanation for the mixed findings regarding the added effect of LD on social status is cultural differences. Most studies conducted in the United States found a difference in social status between children with and without LD (see, e.g., Vaughn et al., 2001), while a Dutch study by Bakker et al. (2007) and the present study did not. Bakker et al. hypothesized that attitudes toward (learning) disabilities, diagnostic practices, and the organization of education might differ across countries, which could be an explanation for the varying results across studies (Kayama, 2010). If children receive, for example, extra instruction outside the classroom, they have fewer opportunities to interact with their classmates. As a consequence, friendships may be less likely to develop, resulting in a lower social status (Bunch \& Valeo, 2004; Vaughn et al., 2001).

Our results do not indicate that teacher liking is unimportant for children with LD. In accordance with other studies, PRTL was found to be predictive of social status (e.g., De Laet et al., 2014; Hughes et al., 2001; Hughes \& Kwok, 2006), even more so for children with a low PAR (cf. Hughes et al., 2014). Therefore, teacher liking can indirectly influence the effects of $\mathrm{LD}$ on social status given the lower PAR of children with LD. Our results showed that a low PAR was also related to a low PRTL. This finding is worrisome since PRTL is found to be even more important for the social status of children with a low PAR. It is essential for teachers to be aware of the influence that they might have on children's social status, particularly for low-achieving children with or without LD.

\section{Limitations and Further Research}

Because of the concurrent nature of the present study, no causal relationships can be assumed. Although negative peer perceptions about low achievement imply that low achievement leads to a lower social status (Kiuru et al., 2012; Vaughn et al., 1990), the effect might also be reversed or reciprocal. Rejection by peers can lead to lower classroom engagement, which could consequently influence achievement negatively (Buhs, Ladd, \& Herald, 2006; Wood, 2007). Regarding the relationship between PRTL and likeability, no causal conclusions can be drawn either. The results of a longitudinal study by De Laet et al. (2014) demonstrated a reciprocal relationship between teacher support and likeability, with more teacher support leading to higher likeability and with higher likeability leading to more teacher support. In addition, the associations between PRTL and likeability might be explained by other factors, such as student behavior (Chang et al., 2007; De Laet et al., 2014). Nonetheless, several studies demonstrated that the effect of a supportive teacher-student relationship on likeability was maintained after controlling for conduct problems, aggression, or prosocial behavior (De Laet et al., 2014; Hughes et al., 2001; Hughes \& Kwok, 2006), indicating that peer perceptions of teacher liking can indeed contribute to likeability. To obtain more insight into the directions of the effects investigated in the present study, longitudinal research is necessary. Although social status is found to be a quite stable construct (Jiang \& Cillessen, 2005), longitudinal data could also offer more insight into how social status develops during the school year.

Although peer nominations have several strengths, such as taking into account the perceptions of multiple raters (Hughes, Zhang, \& Hill, 2006), they have some drawbacks as well. Peer nominations of achievement and teacher liking might be influenced by children's global evaluations about their peers; that is, children may rate peers whom they like higher on all items, simply because they like them (Hughes et al., 2001). However, the results obtained by Hughes et al. (2001) demonstrated little resemblance between peer nominations of teacher support and peer nominations of, for example, athletic ability, suggesting that peer nominations are at least not influenced entirely by global evaluations and are a valuable tool to measure children's perceptions of various constructs.

In further research, it might be worthwhile to analyze the negative and positive nominations making up likeability and popularity separately (Coie, Dodge, \& Coppotelli, 1982). This suggestion is supported by a study by McMichael (1980), which showed that boys with reading difficulties were less often nominated as most liked person but did not differ on negative peer nominations from their peers without reading difficulties. In contrast, Kuhne and Wiener (2010) found similar but opposite effects for positive and negative peer nominations. However, exploratory analysis of the first model, presented here separately for positive and negative social status, did not yield a differing interpretation of the model.

Concerning the generalizability of the results of the present study, one should keep in mind possible cultural differences (as mentioned previously; Bakker et al., 2007) and the age of the children (the focus on fifth-grade children). In some studies, the effects of LD and achievement on social status were shown to increase during primary school and even one school year (Bakker et al., 2007; Kuhne \& Wiener, 2010). However, Estell et al. (2008) found that the effects were stable over time. Some argued that if stigmatizing effects of LD exist, these are likely to diminish during primary school as children become more used to interacting with classmates with LD (Hastings \& Graham, 1995; Nowicki, 2003). Future research should include more age groups to further investigate the varying effects of LD and PAR on social status at different ages. 


\section{Conclusion and Implications}

Despite these limitations, the present study provides insight into the social status of children with LD by considering PAR and PRTL. The associations between LD and social status could completely be explained by the associations between LD and PAR. In addition to being directly related to likeability, PRTL served as a protective factor against low social status for children with low PAR, thus indirectly also potentially benefiting children with LD. If teachers want to improve the social status of children with $L D$, they seem well advised to focus on peer perceptions of low academic achievement in general and not on the LD diagnosis in particular. Teachers can encourage children to tolerate differences between children (Vaughn et al., 2001). Additionally, if all children are perceived as being equally liked by the teacher, regardless of whether they achieve well, this might positively influence the social status of low-achieving children. Although, on average, no direct effect of LD on social status was found in the present study, teachers should, of course, remain aware of possible exceptions. If some children with LD have a low social status because of negative perceptions of classmates toward LDs, it could still be helpful if teachers try to increase classmates' understanding and tolerance of LD (Terras et al., 2009).

\section{Declaration of Conflicting Interests}

The author(s) declared no potential conflicts of interest with respect to the research, authorship, and/or publication of this article.

\section{Funding}

The author(s) disclosed receipt of the following financial support for the research, authorship, and/or publication of this article: This study was financially supported by The Netherlands Organization for Scientific Research (NWO), project number 411-10-915.

\section{References}

American Psychiatric Association. (2013). Diagnostic and statistical manual of mental disorders (5th ed.). Washington, DC: American Psychiatric Association.

Bakker, J. T. A., Denessen, E., Bosman, A. M. T., Krijger, E. M., \& Bouts, L. (2007). Sociometric status and self-image of children with specific and general learning disabilities in Dutch general and special education classes. Learning Disability Quarterly, 30(1), 47-62. doi:10.2307/30035515

Bruininks, V. L. (1978). Actual and perceived peer status of learning disabled students in mainstream programs. The Journal of Special Education, 12(1), 51-58. doi:10.1177/002246697801200109

Buhs, E. S., Ladd, G. W., \& Herald, S. L. (2006). Peer exclusion and victimization: Processes that mediate the relation between peer group rejection and children's classroom engagement and achievement? Journal of Educational Psychology, 98(1), 1-13. doi:10.1037/0022-0663.98.1.1
Bunch, G., \& Valeo, A. (2004). Student attitudes toward peers with disabilities in inclusive and special education schools. Disability \& Society, 19(1), 61-76. doi:10.1080/0968759032000155640

Bursuck, W. (1989). A comparison of students with learning disabilities to low achieving and higher achieving students on three dimensions of social competence. Journal of Learning Disabilities, 22(3), 188-194. doi:10.1177/002221948902200310

Chang, L., Liu, H., Fung, K. Y., Wang, Y., Wen, Z., Li, H., \& Farver, J. M. (2007). The mediating and moderating effects of teacher preference on the relations between students' social behaviors and peer acceptance. Merrill-Palmer Quarterly, 53(4), 603-630. doi:10.1353/mpq.2008.0006

Cillessen, A. H. N., \& Marks, P. E. L. (2011). Conceptualizing and measuring popularity. In A. H. N. Cillessen, D. Schwartz, \& L. Mayeux (Eds.), Popularity in the peer system (pp. 25-56). New York, NY: Guilford Press.

Cillessen, A. H. N., \& Rose, A. J. (2005). Understanding popularity in the peer system. Current Directions in Psychological Science, 14(2), 102-105. doi:10.1111/j.09637214.2005.00343.x

Coie, J. D., Dodge, K. A., \& Coppotelli, H. (1982). Dimensions and types of social status: A cross-age perspective. Developmental Psychology, 18(4), 557-570. doi:10.1037/0012-1649.18.4.557

Davis, J. A. (1971). Elementary survey analysis. Englewood Cliffs, NJ: Prentice Hall.

De Laet, S., Doumen, S., Vervoort, E., Colpin, H., Van Leeuwen, K., Goossens, L., \& Verschueren, K. (2014). Transactional links between teacher-child relationship quality and perceived versus sociometric popularity: A three-wave longitudinal study. Child Development, 85(4), 1647-1662. doi:10.1111/ cdev.12216

Estell, D. B., Jones, M. H., Pearl, R., Van Acker, R., Farmer, T. W., \& Rodkin, P. C. (2008). Peer groups, popularity, and social preference: Trajectories of social functioning among students with and without learning disabilities. Journal of Learning Disabilities, 41(1), 5-14. doi:10.1177/0022219407310993

Farmer, T. W., McAuliffe Lines, M., \& Hamm, J. V. (2011). Revealing the invisible hand: The role of teachers in children's peer experiences. Journal of Applied Developmental Psychology, 32(5), 247-256. doi:10.1016/j.appdev.2011 .04 .006

Fletcher, J. M., Stuebing, K. K., Morris, R. D., \& Lyon, G. R. (2013). Classification and definition of learning disabilities. In H. L. Swanson, K. R. Harris, \& S. Graham (Eds.), Handbook of learning disabilities (pp. 33-50). New York, NY: Guilford Press.

Gelman, A. (2013). Understanding posterior $p$-values. Electronic Journal of Statistics, 7, 2595-2602. Retrieved from http:// citeseerx.ist.psu.edu/viewdoc/download?doi=10.1.1.310.145 $\&$ rep $=$ rep $1 \&$ type $=$ pdf

Greenham, S. L. (1999). Learning disabilities and psychosocial adjustment: A critical review. Child Neuropsychology, 5(3), 171-196. doi:10.1076/chin.5.3.171.7335

Haager, D., \& Vaughn, S. (1995). Parent, teacher, peer, and selfreports of the social competence of students with learning disabilities. Journal of Learning Disabilities, 28(4), 205-215. doi:10.1177/002221949502800403 
Hastings, R. P., \& Graham, S. (1995). Adolescents' perceptions of young people with severe learning difficulties: The effects of integration schemes and frequency of contact. Educational Psychology, 15, 149-159. doi:10.1080/0144341950150204

Hinshaw, S. P. (1992). Academic underachievement, attention deficits, and aggression: Comorbidity and implications for intervention. Journal of Consulting and Clinical Psychology, 60(6), 893-903. doi:10.1037/0022-006X.60.6.893

Hox, J. J. (2010). Multilevel analysis: Techniques and applications. New York, NY: Routledge.

Hox, J. J., Moerbeek, M., Kluytmans, A., \& Van de Schoot, R. (2014). Analyzing indirect effects in cluster randomized trials. The effect of estimation method, number of groups and group sizes on accuracy and power. Frontiers in Psychology, 5, 1-7. doi:10.3389/psyg.2014.00078

Hughes, J. N., Cavell, T. A, \& Willson, V. (2001). Further support for the developmental significance of the quality of the teacher-student relationship. Journal of School Psychology, 39(4), 289-301. doi:10.1016/S0022-4405(01)00074-7

Hughes, J. N., Im, M. H., \& Wehrly, S. E. (2014). Effect of peer nominations of teacher-student support at individual and classroom levels on social and academic outcomes. Journal of School Psychology, 52(3), 309-322. doi:10.1016/j.jsp.2013.12.004

Hughes, J. N., \& Kwok, O. (2006). Classroom engagement mediates the effect of teacher-student support on elementary students' peer acceptance: A prospective analysis. Journal of School Psychology, 43(6), 465-480. doi:10.1016/j.jsp.2005.10.001

Hughes, J. N., Zhang, D., \& Hill, C. R. (2006). Peer assessments of normative and individual teacher-student support predict social acceptance and engagement among low-achieving children. Journal of School Psychology, 43(6), 447-463. doi:10.1016/j.jsp.2005.10.002

Jiang, X. L., \& Cillessen, A. H. N. (2005). Stability of continuous measures of sociometric status: A meta-analysis. Developmental Review, 25(1), 1-25. doi:10.1016/j. dr.2004.08.008

Kaplan, D., \& Depaoli, S. (2012). Bayesian structural equation modeling. In R. H. Hoyle (Ed.), Handbook of structural equation modeling (pp. 650-673). New York, NY: Guilford Press.

Kavale, K. A., \& Forness, S. R. (1996). Social skill deficits and learning disabilities: A meta-analysis. Journal of Learning Disabilities, 29(3), 226-237. doi:10.1177/002221949602 900301

Kavale, K. A., \& Mostert, M. P. (2004). Social skills interventions for individuals with learning disabilities. Learning Disability Quarterly, 27(1), 31-43. doi:10.2307/1593630

Kayama, M. (2010). Parental experiences of children's disabilities and special education in the United States and Japan: Implications for school social work. Social Work, 55(2), 117125. doi:10.1093/sw/55.2.117

Kiuru, N., Poikkeus, A. M., Lerkkanen, M. K., Pakarinen, E., Siekkinen, M., Ahonen, T., \& Nurmi, J. E. (2012). Teacherperceived supportive classroom climate protects against detrimental impact of reading disability risk on peer rejection. Learning and Instruction, 22(5), 331-339. doi:10.1016/j. learninstruc.2011.12.003

Kleijnen, R., Bosman, A., De Jong, P., Henneman, K., Pasman, J., Paternotte, A., ... Wijnen, F. (2008). Diagnose en behandeling van dyslexie: Brochure van de Stichting Dyslexie
Nederland [Diagnosis and treatment of dyslexia: Brochure of the Dutch Dyslexia Foundation]. Bilthoven, Netherlands: Stichting Dyslexie Nederland.

Klugkist, I., van Wesel, F., \& Bullens, J. (2011). Do we know what we test and do we test what we want to know? International Journal of Behavioral Development, 35(6), 550-560. doi: $10.1177 / 0165025411425873$

Kuhne, M., \& Wiener, J. (2010). Stability of social status of children with and without learning disabilities. Learning Disability Quarterly, 23(1), 64-75. doi:10.2307/1511100

La Greca, A. N., \& Stone, W. L. (1990). LD status and achievement: Confounding variables in the study of children's social status, self-esteem, and behavioral functioning. Journal of Learning Disabilities, 23(8), 483-490. doi:10.1177/002221949002300806

Lease, A., Musgrove, K., \& Axelrod, J. (2002). Dimensions of social status in preadolescent peer groups: Likeability, perceived popularity, and social dominance. Social Development, 11(4), 508-533. doi:10.1111/1467-9507.00213

McMichael, P. (1980). Reading difficulties, behavior, and social status. Journal of Educational Psychology, 72(1), 76-86. doi:10.1037//0022-0663.72.1.76

Muthén, B. (2010). Bayesian analysis in Mplus: A brief introduction. Unpublished manuscript. Retrieved from https://www. statmodel.com/download/IntroBayesVersion\%203.pdf

Muthén, B., \& Asparouhov, T. (2012). Bayesian structural equation modeling: A more flexible representation of substantive theory. Psychological Methods, 17(3), 313-335. doi:10.1037/ a0026802

Muthén, L. K., \& Muthén, B. O. (1998-2012). Mplus user's guide (7th ed.). Los Angeles, CA: Muthén \& Muthén.

Nelson, S. E., \& Dishion, T. J. (2004). From boys to men: Predicting adult adaptation from middle childhood sociometric status. Development and Psychopathology, 16(2), 441-459. doi:10.1017/S0954579404044608

Nowicki, E. A. (2003). A meta-analysis of the social competence of children with learning disabilities compared to classmates of low and average to high achievement. Learning Disabilities Quarterly, 26(3), 171-187. doi:10.2307/1593650

Nowicki, E. A. (2012). Intergroup evaluations and norms about learning ability. Social Development, 21(1), 130-149. doi:10.1111/j.1467-9507.2011.00614.x

Nowicki, E. A., Brown, J., \& Stepien, M. (2014). Children's thoughts on the social exclusion of peers with intellectual or learning disabilities. Journal of Intellectual Disability Research, 58(4), 346-357. doi:10.1111/jir.12019

Scruggs, T. E., \& Mastropieri, M. A. (2002). On babies and bathwater: Addressing the problems of identification of learning disabilities. Learning Disability Quarterly, 25(3), 155-168. doi: $10.2307 / 1511299$

Statistics Netherlands. (2015). Gezondheidsmetingen kinderen, 2001-2013 [Health measurements children]. Retrieved from http://statline.cbs.nl/Statweb/publication/?DM=SLNL\&PA= 70129 ned $\& D 1=a \& D 2=a \& D 3=0,11 \& D 4=0 \& D 5=a \& H D R=T$ $\& \mathrm{STB}=\mathrm{G} 3, \mathrm{G} 2, \mathrm{G} 4, \mathrm{G} 1 \& \mathrm{VW}=\mathrm{T}$

Terras, M. M., Thompson, L. C., \& Minnis, H. (2009). Dyslexia and psycho-social functioning: An exploratory study of the role of self-esteem and understanding. Dyslexia, 15(4), 304327. doi: $10.1002 /$ dys.386 
Troop-Gordon, W., Visconti, K. J., \& Kuntz, K. J. (2010). Perceived popularity during early adolescence: Links to declining school adjustment among aggressive youth. Journal of Early Adolescence, 31(1), 125-151. doi:10.1177/027431610384488

Valås, H. (1999). Students with learning disabilities and lowachieving students: Peer acceptance, loneliness, self-esteem, and depression. Social Psychology of Education, 3(3), 173192. doi:10.1023/A:1009626828789

Van de Schoot, R., Denissen, J., Neyer, F. J., Kaplan, D., Asendorpf, J. B., \& Van Aken, M. A. G. (2013). A gentle introduction to Bayesian analysis: Applications to developmental research. Child Development, 85(3), 842-860. doi:10.1111/cdev.12169

Van de Schoot, R., \& Depaoli, S. (2014). Bayesian analyses: Where to start and what to report. European Health Psychologist, 16(2), 75-84. Retrieved from http://www.ehps.net/ehp/index. php/contents/article/view/ehp.v16.i2.p75

Van Luit, J. E. H., Bloemert, J., Ganzinga, E. G., \& Mönch, M. E. (2012). Protocol dyscalculie: Diagnostiek voor gedragskundigen [Protocol dyscaluclia: Diagnostics for psychologists]. Doetinchem, Netherlands: Graviant.

Vannatta, K., Gartstein, M. A., Zeller, M., \& Noll, R. B. (2009). Peer acceptance and social behavior during childhood and adolescence: How important are appearance, athleticism, and academic competence? International Journal of Behavioral Development, 33(4), 303-311. doi: $10.1177 / 0165025408101275$

Vaughn, S., Elbaum, B., \& Boardman, A. G. (2001). The social functioning of students with learning disabilities: implications for inclusion. Exceptionality, 9(1), 47-65. doi:10.1080/09362 835.2001 .9666991
Vaughn, S., Elbaum, B. E., \& Schumm, J. S. (1996). The effects of inclusion on the social functioning of students with learning disabilities. Journal of Learning Disabilities, 29(6), 598-608. doi:10.1177/002221949602900604

Vaughn, S., Haager, D., Hogan, A., \& Kouzekanani, K. (1992). Self-concept and peer acceptance in students with learning disabilities: A four- to five-year prospective study. Journal of Educational Psychology, 84(1), 43-50. doi:10.1037/00220663.84.1.43

Vaughn, S., Hogan, A., Kouzekanani, K., \& Shapiro, S. (1990). Peer acceptance, self-perceptions, and social skills of learning disabled students prior to identification. Journal of Educational Psychology, 82(1), 101-106. doi:10.1037//00220663.82.1.101

Waitoller, F. R., \& Artiles, A. J. (2013). A decade of professional development research for inclusive education: A critical review and notes for a research program. Review of Educational Research, 83(3), 319-356. doi:10.3102/0034654313483905

Walker, A., \& Nabuzoka, D. (2007). Academic achievement and social functioning of children with and without learning difficulties. Educational Psychology, 27(5), 635-654. doi:10.1080/01443410701309175

Willcutt, E. G., Betjemann, R. S., Pennington, B. F., Olson, R. K., Defries, J. C., \& Wadsworth, S. J. (2007). Longitudinal study of reading disability and attention-deficit/hyperactivity disorder: implications for education. Mind, Brain, and Education, l(4): 181-192. doi:10.1111/j.1751-228X.2007.00019.x

Wood, J. J. (2007). Academic competence in preschool: Exploring the role of close relationships and anxiety. Early Education and Development, 18(2), 223-242. doi:10.1080/104092807 01282868 